PSICOLOGIA, SAÚDE \& DOENÇAS, 2021, 22(1), 252-269

ISSN - 2182-8407

Sociedade Portuguesa de Psicologia da Saúde - SPPS - www.sp-ps.pt

DOI: http://dx.doi.org/10.15309/21psd220122

\title{
THEORETICAL-CONCEPTUAL ARTICULATION BETWEEN THE HITOP MODEL AND POSITIVE PSYCHOLOGY CONSTRUCTS
}

\author{
Sérgio Oliveira ${ }^{1}$, Felipe Corrêa ${ }^{1}$, Wladimir Fonseca ${ }^{1}$, Daniela Zanini ${ }^{1}$, Germano Esteves ${ }^{1}$, Giulia Melo ${ }^{1}$, \\ Sebastião Pereira Júnior ${ }^{1}$, Thiago Nascimento ${ }^{1}, \&$ Cristiane Faiad ${ }^{1}$
${ }^{1}$ Institute of Psychology, University of Brasília, Brazil, sesoliveira@unb.br, minottofelipe1@gmail.com, wladbsb@gmail.com, dazanini@yahoo.com, germanoesteves@unirv.edu.br, giulia.veiga.15@gmail.com, sebavenancio25@gmail.com,tgn.1980@gmail.com,crisfaiad@gmail.com

\begin{abstract}
Conceptual articulation between health and mental illness is an activity that demands theoretically consistent models. Hierarchical Taxonomy of Psychopathology (HiTOP) is a model for understanding multidimensional mental disorders organized by a quantitative logic. By contrast, positive psychology provides a wide range of psychological factors to understand mental health. Therefore, to propose a theoretical-conceptual articulation between HiTOP and positive psychology, this research consists of two studies. Study I sought to present the empirical findings and theoreticalconceptual discussions of the HiTOP model through a systematic review conducted in the Google Scholar, PsycINFO, and PubMED databases, using the descriptors "Hierarchical Taxonomy of Psychopathology" OR "HiTOP" in the period between 2017 and 2020. Study II aimed to discuss the possible relationships between the HiTOP domains and the positive psychology constructs, seeking to articulate the psychological factors that promote mental health and their corresponding psychopathological manifestations. Overall, it was observed that the scientific community shows a growing interest in studying the HiTOP model and that positive psychological resources can represent protective and intervention factors for symptoms and psychopathological traits. Finally, there is a need for more empirical evidence to support the structure of HiTOP, as well as evidence of models that integrate psychological factors promoting health and mental illness.
\end{abstract}

Keywords: psychopathology, positive psychology, risk factors, protective factors, mental health.

\section{ARTICULAÇÃO TEÓRICO-CONCEITUAL ENTRE O MODELO HITOP E CONSTRUTOS DA PSICOLOGIA POSITIVA}

RESUMO: Articular saúde e doença mental é uma atividade que demanda modelos teoricamente consistentes. De um lado, o Hierarchical Taxonomy of Psychopathology (HiTOP) é um modelo de compreensão de transtornos mentais multidimensional organizado por uma lógica quantitativa. Por outro, a psicologia positiva fornece uma ampla gama de fatores psicológicos para compreensão da saúde mental. Assim, visando

Campus Darcy Ribeiro, Universidade de Brasília, ICC-Sul, Sala A1 028/4, CEP 70910-900, email: sergioeduardos.oliveira@gmail.com 
Sérgio Oliveira, Felipe Corrêa, Wladimir Fonseca, Daniela Zanini, Germano Esteves, Giulia

Melo, Sebastião Pereira Júnior, Thiago Nascimento, \& Cristiane Faiad

propor uma articulação teórico-conceitual entre o HiTOP e a psicologia positiva, a presente pesquisa constitui-se de dois estudos. O primeiro estudo um objetivou apresentar os achados empíricos e as discussões teórico-conceituais do modelo HiTOP por meio de uma revisão sistemática da literatura realizada nas bases de dados Google Scholar, PsycINFO e PubMED, utilizando os descritores "Hierarchical Taxonomy of Psychopathology" OR "HiTOP" no período entre 2017 e 2020. O segundo estudo objetivou discutir as possíveis relações entre os domínios do HiTOP e os construtos da psicologia positiva, buscando articular os fatores psicológicos promotores de saúde mental e as manifestações psicopatológicas correspondentes. De modo geral, observa-se que há um crescente interesse da comunidade científica em estudar o modelo HiTOP e que os recursos psicológicos positivos podem ser fatores de proteção e de intervenção para sintomas e traços psicopatológicos de acordo com esse modelo. Por fim, é indicada a necessidade de mais evidências empíricas que suportem a estrutura do HiTOP, assim como estudos que validem um modelo integral de saúde e doença mental.

Palavras-Chave: psicopatologia, psicologia positiva, fatores de risco, fatores de proteção, saúde mental.

Recebido em 17 de setembro de 2020/ Aceite em 23 de fevereiro de 2021

The relationship between mental health and disease is complex and dynamic due to the multiple factors involved in this relationship. Part of this complexity may be related to the manner in which the mental disease is understood. Traditionally, the main classification systems for mental disorders, especially the International Classification of Diseases (ICD), from the World Health Organization (WHO), and the Diagnostic and Statistical Manual of Mental Disorders (DSM), from the American Psychiatric Association (APA), propose a taxonomy based on a categorical model. These classification systems were created to better organize the field that, until then, had difficulty communicating between different researchers, which in turn hindered the progress of studies (Krueger \& Piasecki, 2002). Currently, based on scientific evidence, these systems are in the process of transformation, since dimensional models of psychopathology are presenting greater evidence of validity and reliability (Markon et al., 2011).

The categorical model of the classification of mental disorders understands psychopathologies as independent categories (Millon, 1991), with well-defined frontiers between them. The diagnostic operationalization of this model is based on a dichotomous perspective, in which an individual is classified or not in one or more categories (Wright et al, 2013). The frontiers of disorders are defined by a wide range of criteria or symptoms. These criteria are developed in an attempt to clearly delineate the disorder and produce a homogeneous diagnostic group. However, the polythetic nature of this model, that is, the existence of a greater number of criteria than that necessary for the classification in a diagnostic category, results in a large intragroup heterogeneity (Salum et al., 2018). In this sense, the people classified in a single diagnostic category present a broad variability amongst themselves in terms of the appearance of symptoms.

Another common problem related to the categorical model refers to comorbidity. This term is used to describe the co-occurrence of distinct mental disorders, apparently interacting amongst themselves, but each with its own etiology and pathology (Widiger \& Gore, 2015). The phenomenon of comorbidity in different mental disorders has been investigated for some years and postulates the impossibility of a diagnostic category being seen as pure, in other words, it is not associated with any other at any level (Clark et al., 1995; Widiger \& Sankis 2000).

The problems of intragroup heterogeneity and of frontiers that overlap among groups (Widiger \& Mullins-Sweatt, 2012), much like the uncertain limits among the wide range of classes of mental 
disorders (anxiety, mood, schizophrenia, personality disorders) (Widiger \& Sankis, 2000), are examples of limitations that weaken the validity and reliability of the categorical model of the classification of mental disorders. As an alternative to this diagnostic model, researchers have observed the superiority of dimensional models over categorical models. This presents a change in paradigm from the qualitative to the quantitative, given that the advance in statistical models has allowed for a well-founded (Krueger \& Piasecki, 2002) and clinically useful (Verheul, 2005) empirical understanding of psychopathology.

Part of the origin of dimensional models of psychopathology are related to comorbidity studies. These studies begin to be systematized as with the publication of the third edition of the DSM (American Psychiatric Association, 1980) and move forward when factor analysis is applied (Clark et al., 1995). Based on a two-dimensional model of child psychopathology, whose factors were defined as Internalizing and Externalizing Problems, Krueger et al. (1998) investigated the factorial structure of mental disorders in a sample of adults and found a similar model. The Internalizing dimension joined the disorders of mood and anxiety, while the Externalizing dimension included the disorders related to substance abuse and antisocial personality disorder. Other studies have shown empirical support for a three-factor model that adds the Psychosis dimension (or Thought Disorder) to the dimensions of Internalizing and Externalizing symptoms (Wright et al., 2013). With the development of studies on this theme, researchers have observed the possibility of a second-order model, in which an overall factor of psychopathology could explain the psychopathological expression of people prone to present symptoms of both factors. Caspi et al. (2014) found evidence for the overall factor of psychopathology, which they called the p-factor.

The differences between the analytical methods of the studies that investigate the overall factor (van Bork et al., 2017), as well as the effect of the method (positive covariation among the variables), tends to support inquiries regarding the existence of an overall psychopathological factor. It is in this context that an international consortium of researchers from different fields, including psychology, psychiatry, and philosophy, was formed to propose and research a new taxonomic system of mental disorders (Krueger et al, 2018) that minimizes the shortcomings observed in previous models (Kotov et al., 2020). Known as The Hierarchical Taxonomy of Psychopathology (HiTOP) consortium, these researchers propose the HiTOP model, which is characterized by an organized hierarchical multidimensional system. Figure 1 presents the model's hierarchical structure (Kotov et al., 2017).

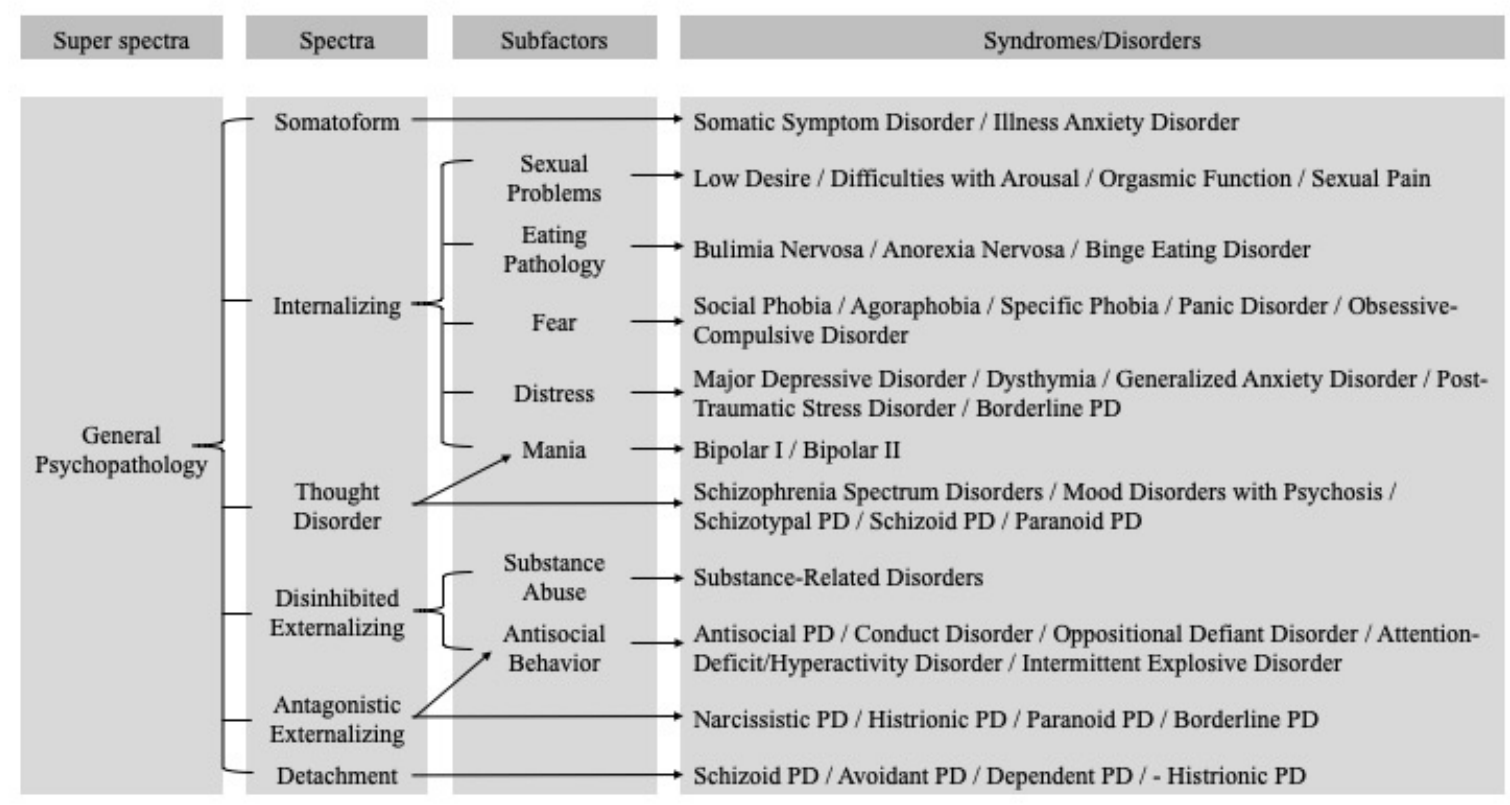

Figure 1. Representation of the Hierarchical Taxonomy of Psychopathology (HiTOP). Source: Kotov et al. (2017). 
At the top of the model is an overall psychopathological factor. Next, the six spectra of psychopathology are listed, as follows: internalizing (or negative affection), thought disorder (or psychoticism), disinhibited externalizing, antagonistic externalizing, detachment, and somatoform (Kotov et al., 2017). Some of these spectra contain subfactors, which some can share a variance with another spectrum. The HiTOP model does not seek to operate at the level of disorders, but rather at the level of components and traits. Given the familiarity of the researchers and clinicians with the diagnostic categories of mental disorders, the disorders are listed in order to allow for a swift comprehension of the contents of these spectra and factors. The components and traits represent the maladaptive expression of the psychological functioning. Psychopathology thus becomes defined in terms of a dimensional profile of the maladaptive psychological function.

The HiTOP model proposes an empirical system based on the explanation of the comorbidity, considering the way in which the different syndromes ad symptoms overlap in its phenomenology (Mullins-Sweatt et al., 2020). This hierarchical model seems to be able to accommodate and organize the prior theoretical models and offer the possibility of a path toward the construction of a consensus for researchers in the field of psychopathology (Latzman et al., 2020). Moreover, the clinical use of the dimensional models of psychopathology have been reported in other studies (Kotov et al., 2020), as has their superiority in terms of validity and reliability (Kotov et al., 2020).

\section{The Present Study}

In the context of the relationship between health and disease, and considering the advent of a multidimensional and hierarchical model of psychopathology, the present study seeks to debate the possible relationships between the HiTOP model and the constructs of interest of Positive Psychology, in an attempt to design a perspective of balance between the psychopathological symptoms and the positive psychological resources. To achieve this, considering that the HiTOP model is relatively recent (Kotov et al., 2017), it was deemed necessary to conduct a systematic review of the literature to better understand the scientific discussions surrounding the HiTOP model (Study I). This study then aimed to discuss the constructs of Positive Psychology that could contrast with the pathological poles of the HiTOP model, in an attempt to identify possible psychological factors that can be both protective and useful for protection, promotion, and/or intervention in mental health programs (Study II).

\section{Study I: A Systematic Review of the Literature concerning the HiTOP model}

The present systematic review proposed to survey and analyze the scientific production regarding the HiTOP model. The core aim was to present the empirical findings and the theoretical-conceptual discussions about the model through a systemic analysis of the manuscripts that considered the HiTOP model as the core aspect of the debate and that were published in scientific journals.

\section{METHOD}

This review was based on the Preferred Reporting Items for Systematic Reviews and MetaAnalyses (PRISMA) model, a protocol that applies a four-phase flow chart (Identification, Selection, Eligibility, and Inclusion) and a checklist that consists of 27 items considered essential for an adequate and transparent communication of the data in a systematic review (Galvão et al., 2015). In the Identification phase, the existing scientific production was accessed through the PubMED, PsycINFO, and Google Acadêmico databanks, using Harzing's Publish or Perish software, version 
7.21. For this search, in all of the platforms, the descriptor "Hierarchical Taxonomy of Psychopathology" OR HiTOP was used. The data were accessed in June 2020.

In the selection phase, duplicates were removed and the register for the triage of articles was established. At this point, the titles were analyzed and the articles that treated themes that were not related to Psychopathology or Psychodiagnosis were excluded. After this exclusion, the Eligibility phase was begun to perform a full evaluation of the articles.

The following inclusion criteria were adopted in this phase of the study: articles that used the HiTOP model, published in English, Portuguese, or Spanish, and that were available in full. Exclusion criteria included: articles that cite the HiTOP model, but do not focus on the model, that is the description of the model or discussion about it were not the main goal of the article; works written in languages other than the three mentioned above; articles that were not fully available; texts that were not published in scientific journals; studies that referred to the HiTOP acronym but with another context and meaning; articles that cited HiTOP but that were not related to Psychopathology and/or Psychodiagnosis; and unfound titles.

After the final Inclusion phase, this study identified basic features, such as: the country and year of publication; overall aim; nature of the article (if theoretical or empirical); instruments used and the sample in which the model was applied; studied and/or measured factors; main results; and overall limitations of the studies. With this identification it was possible to define categories to organize the publications that present similarities.

\section{RESULTS}

This study identified 1,037 hits in the aforementioned databases, with 996 in the Google Scholar, 37 in the PsycINFO, and 4 in the PubMED databases. After the removal of duplicates, the number was reduced to 1,006. After the reading of the titles and abstracts, another 954 studies were removed, resulting in a total of 52 articles to be fully assessed. After applying the exclusion criteria, the final sample for analysis included 25 publications. Figure 2 presents the flow chart of the applied review system. 
Sérgio Oliveira, Felipe Corrêa, Wladimir Fonseca, Daniela Zanini, Germano Esteves, Giulia Melo, Sebastião Pereira Júnior, Thiago Nascimento, \& Cristiane Faiad

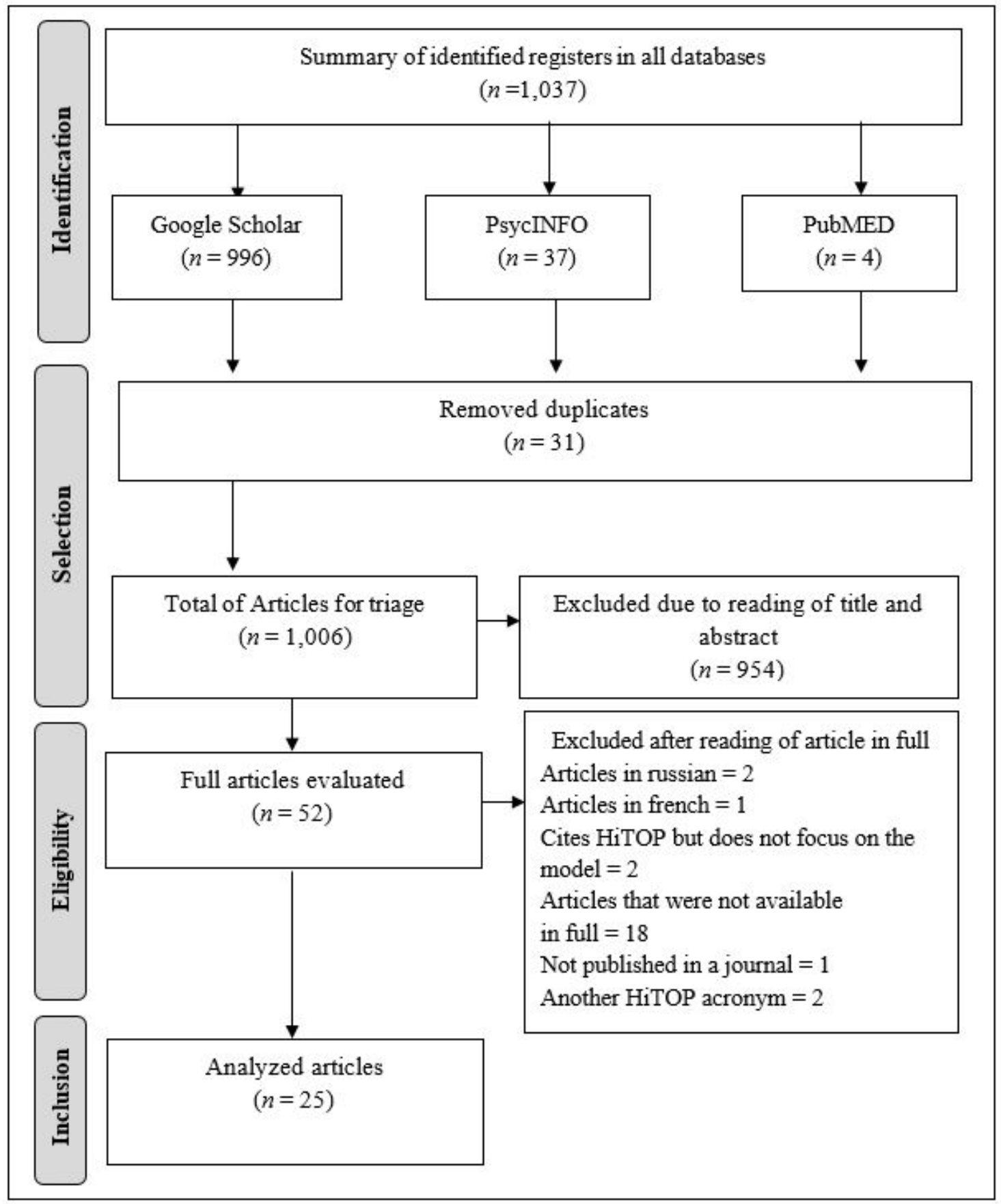

Figure 2. Flow chart

\section{Year and Country of Publication of the Articles}

The first analysis concerned the publications years of the selected papers and the countries in which the journals are published. The analyzed studies were dated as of 2017 , the same year in which the model was first published. The two following years witnessed a significant increase in studies published on the theme, with six (24\%) in 2018 and seven (28\%) in 2019. The year of 2020, though incomplete, has 11 publications, totaling $44 \%$ of the total number of publications, indicating that it is a subject that has become popular within the field of science and has spread quickly. Regarding the countries, it is important to note that the HiTOP model, as it is an international consortium, counts on a collaboration of researchers from around the world. A total of nine $(36 \%)$ of the reviewed articles consist of international collaborations; however, this distribution does not show an egalitarian 
structure: of the nine articles, seven were constructed by American authors. Adding to this data, nine articles were published only by authors from American Universities, in such a way that, in total, 16 studies (64\%) presented a full or majority influence from American researchers. Other countries that stand out are Brazil, with four (16\%) and Germany, with two (8\%) publications.

\section{Nature of the Articles (Theoretical/Empirical) and Studied Factors}

Of the 25 studied articles, fifteen (60\%) were on a theoretical basis and ten (40\%) were theoreticalempirical grounded. This proportion between theoretical and empirical articles reflects a model that is under construction, since what was observed were studies that aimed to discuss, justify, and expand the theoretical bases of the model, as well as empirical studies aimed at observing the behavior and structuring of the constructs within the model.

Of the theoretical papers, four (16\% in total) seek to present the features of the HiTOP model, as well as its process of construction, hierarchical structure, limitations, and future indications for research (Conway et al., 2019; Kotov et al., 2017; Kotov et al., 2018; Krueger et al., 2018). Next, in three instances (12\% of the total), were the papers that discussed the integration of the HiTOP model with neuroscientific studies, and the possible contributions of the model for the researchers in this field (Latzman et al, 2020; Perkins et al., 2019; Perkins et al., 2020). Two categories present two instances ( $8 \%$ of the total) each: studies that criticize the HiTOP model, presenting counter-arguments to the supposed advances of the model (Reed, 2018; Wittchen \& Beesdo-Baum, 2018), and studies that discussed the relationship between the HiTOP model and an alternative model for personality disorders (Meehan et al., 2019; Widiger et al., 2019;), which was presented in Section III of the fifth edition of DSM (DSM-5; American Psychiatric Association, 2013). The remainder of the theoretical studies, all with one instance each (4\%), treated the following categories: integration of the HiTIOP model with clinical practice (Ruggero et al., 2019); relating the HiTOP model to other paradigms of dimensional psychopathology (Achenbach, 2020); the psychotic spectrum and the guidelines to treat this specific disorder within the HiTOP model (Kotov et al., 2020); and an overall study on personality disorders and how these are presented within the HiTOP model (Mullins-Sweatt, 2020).

The theoretical-empirical studies, by contrast, present a thematic distribution as follows. First, seven articles were identified (28\%) that deal with empirical studies on personality disorders, investigating their factorial structure and their adaptation to the HiTOP model (Bailey \& Finn, 2019; Carvalho et al., 2020; Carvalho et al., 2019; Carvalho et al., 2018; Longenecker et al., 2020; Pianowski et al., 2019; Sellbom et al., 2019). Furthermore, three categories were created, each one containing only one study: one study about the p-factor of psychopathology and its connection with the HiTOP model (Hyland et al., 2020); one study that investigated the racial and ethnic bias in the prevalence of disorders, considering a HiTOP model diagnosis (He \& Li, 2020); and, finally, one article that treats the HiTOP integration with another dimensional model that deals with psychopathology (Jacobs et al., 2018).

\section{Material}

The most commonly used instrument in the theoretical-empirical studies was the Personality Inventory for DSM-5 (PID-5) (Krueger et al., 2012), present in five studies. Another important instrument was the Dimensional Clinical Personality Inventory 2 (IDCP-2), a review of a measure based originally on Million's Dimensional Model of Psychopathology (Carvalho \& Primi, 2018) and which serves as the basis for the four Brazilian studies in this review. Another instrument used in the articles was the Five Factor Histrionic Inventory (FFHI) (Tomiatti et al., 2012), based on the fivefactor model of personality. 
Sérgio Oliveira, Felipe Corrêa, Wladimir Fonseca, Daniela Zanini, Germano Esteves, Giulia

Melo, Sebastião Pereira Júnior, Thiago Nascimento, \& Cristiane Faiad

\section{Main Results from the Studies}

As regards the theoretical articles, the majority of publications were those which compiled important studies and data to justify the construction of an evidence-based model. Such justifications can be found in the comparison of the model with the current diagnostic systems present in academia today; the possibilities of overcoming the pinpointed problems and possible links; the integration of the HiTOP model with other approaches, especially with neuroscience studies; and the integration with clinical practice, conducted in a cross-sectional manner within the publications. In addition, there were also studies that presented the hierarchy proposed by the consortium and its levels, and which generate a debate on the structure, in its overall aspect and particular disorders. The debate about the hierarchical framework is still ongoing and studies are being suggested in the field.

As regards the empirical studies, the results tend to indicate proof of the validity of the model, both as regards particular disorders and in structural terms. The studies related to personality disorders added empirical evidence regarding the common structure of the HiTOP model, which integrates symptoms and traits. Another focus of empirical investigation was the overall factor of psychopathology and the ethnic relationships that must be considered in this model.

\section{DISCUSSION}

The literature concerning the HiTOP model tends to support its formation. The articles analyzed in this review, in an overall manner, agree that HiTOP represents a step forward in the classification of the psychopathologies and that it has potential to better structure research and clinical practices (Conway et al., 2019; Kotov et al., 2017; Kotov et al., 2018; Krueger et al., 2018). Even the articles of Wittchen and Beesdo-Baum (2018) and of Reed (2018), which are dedicated to pointing out the limitations of the model, do not fail to consider the progress contained in this proposal. A model that is scientifically based and integrated in the clinical reality can represent a contemporary answer to the research and clinical challenges regarding patients with mental disorders. Nevertheless, the change from the qualitative and categorical paradigm to a quantitative and dimensional system can face major resistance from different categories of professionals and fields of knowledge.

Despite this possible resistance, it is well-known that the dimensional models present validity and clinical utility. Ruggero et al. (2018) propose principles that seek to guide clinical practice based on the HiTOP model, as well as advantages and limitations linked to the theme. These authors highlight the advantage of using a model that explicitly overcomes the clinical difficulty of unclear frontiers among mental disorders and the differentiation between normality and pathology. Also related to the clinical applicability of the model, Mullins-Sweatt et al. (2020) compiled a wide range of treatment techniques and arranged them according to the spectra of the HiTOP model. The authors emphasized the need to organize a taxonomy of techniques that are applicable to the model, in such a way as to generate a hypothesis of the relationship among the traits of the disorders. It would be difficult to make the application of the model more tangible. The proposal of the HiTOP model presents some similarities with the Research Domain Criteria (RDoC) approach, which focuses on the neurological aspects of diagnosis (Conway et al., 2019; Kotov et al., 2018). The relationships between the neurobiological constructs and the HiTOP model can represent a step towards the validity and refining of the model, since such constructs stem from empirical data and can aid in the understanding of the nature of the dimensions (Perkins et al, 2020; Perkins et al., 2019). Moreover, the integration of these models would also be beneficial for neuroscientific studies of psychopathology, especially those related to psychopharmacology (Latzman \& DeYoung, 2020), since it would furnish more informative clinical phenotypes. 
The HiTOP hierarchical structure is under empirical investigation, though the previous findings point to a validity of the proposed arrangement. The overall factor of psychopathology has proven to be an important element in the description of people with high vulnerability to the experience and expression of mental and behavioral symptoms. Hyland et al. (2020) contributed to this debate, pointing out methodological questions that could aid in the interpretation of this factor.

\section{Limitations of Study}

The present review presents some limitations that should be pointed out. The first refers to the limited number of databases consulted in this study. Although the selected databases cover a wide range of audiences and subjects, it is believed that the search for keywords in other databases could result in finding other publications on the theme. As there are studies on this theme published in languages other than those mentioned herein, the language criterion also represents a limitation to this study. Finally, another limitation is related to the lack of access to full articles. In this study, 18 articles were unavailable in their full form, a number that is nearly the same as the number of selected articles in this review. This shows that other information does exist regarding the HiTOP model that could not be accessed and therefore limited the results found in this review. We would suggest that new searches in the literature be conducted in such a way as to complement the findings from this review.

\section{Final Considerations}

Based on this literature review, it was observed that there is a growing interest in the scientific community to study the HiTOP model, which has proven to be a potential substitute to the categorical model of psychopathology. The model proposes advances in the questions of diagnostic validity and reliability, and proposes a validated scientific approach to handle the problems of comorbidity. In any case, studies that empirically test the structure of the model are still scarce, as are their impacts on diagnostic and interventional clinics.

\section{Study II: Relationships Between the Spectra of the HiTOP Model and the Constructs of Positive Psychology}

The present study, using a theoretical-conceptual basis, seeks to discuss the relationships between the domains of the HiTOP model and the constructs of Positive Psychology, in an attempt to establish an articulation between the psychological factors that promote mental health and psychopathological manifestations. This articulation allows for the formulation of programs for the prevention and promotion of mental health, considering the main positive psychological domains associated with the contents of the HiTOP model spectra.

\section{The Somatoform Spectra}

As the name suggests, the Somatoform spectra is characterized by the physical symptoms with subjacent emotional problems. People in this spectrum tend to present, for example, pains from headaches and gastrointestinal problems. It is important to remember that this spectrum lacks robust proof of validity from the HiTOP model (Kotov et al., 2017). Regardless of the continuance or not of this spectrum within the model, it is possible to verify that there are some positive psychological factors related to somatoform symptoms. For example, Karampas et al. (2016), in a sample of Greek military soldiers, verified that positive emotions and resilience were related to better psychosomatic 
health. Considering that the psychosomatic complaints also contain subjacent emotional problems, the experience of positive affection tends not to cause physical problems. Moreover, the resilience, as a psychological resource of recovery after the occurrence of stressful events, can perform a protective role in relation to psychosomatic complaints, since it can influence the process of the experience and expression of negative affection so as to avoid somatic problems.

Self-compassion, understood as a healthy and positive self-guided attitude were observed in lower levels in a sample of patients with somatic symptom disorders from the Netherlands (Dewsaran-van der Ven et al., 2018). Patients with somatic symptom complaints seem to be prone to make severe self-criticism; to individualize their experiences, believing that they are isolated from human experiences; and to identify themselves strictly according to their painful thoughts and feelings. These attitudes, contrary to the dimensions of self-compassion, from the viewpoint of Dewsaran-van der Ven et al. (2018), can be the target of intervention. Remembering that interventions in positive psychology have positive effects in patients with somatic symptom and psychiatric complaints (Chakhssi et al., 2018). Figure 3 illustrates the links between the spectra of the HiTOP model and the positive psychological factors.

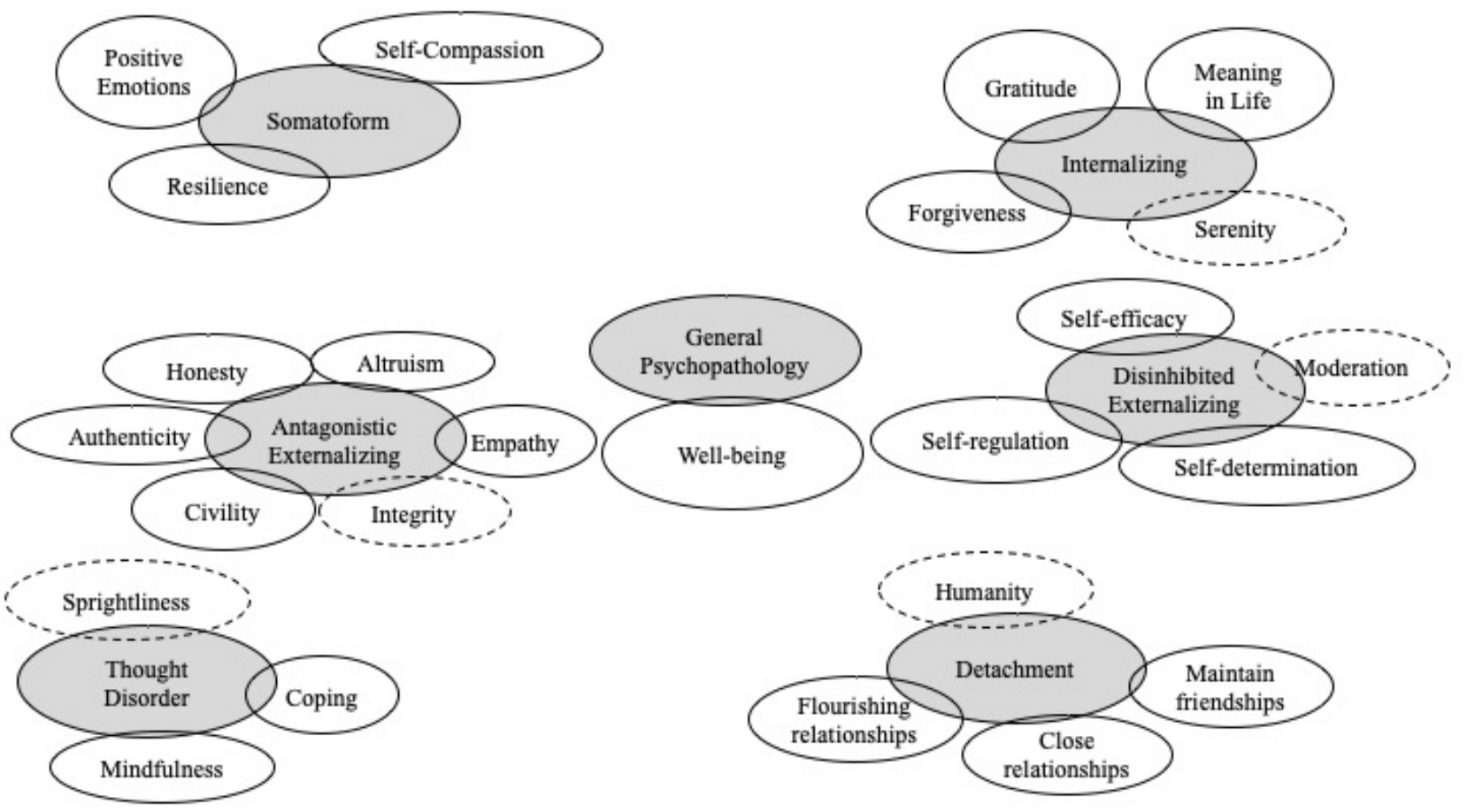

Figure 3. Comparisons of the Spectra of HiTOP with Positive Psychological Factors

Legend: Gray circles represent the HiTOP spectra; white circles represent the positive psychological factors; white circles with dotted lines represent positive personality traits.

\section{The Internalizing Spectra}

The Internalizing spectra is characterized by the experience and expression of negative emotions, such as depression, anxiety, and distress (Kotov et al., 2017). This psychopathological domain can be negatively correlated with gratitude. People willing to recognize and appreciate the benefits that they receive in their lives, tend to present fewer symptoms of depression (Disabato et al., 2017) and anxiety (Petrocchi \& Couyoumdjian, 2015). The feeling of gratitude is associated with the experiences of positive affection (Lin, 2019), that is, the contrary of the negative affection experienced in the internalizing symptoms. Another positive psychological factor that seems to oppose this domain is forgiveness. People that are capable of self-forgiveness and to forgive others tend to present fewer 
symptoms of depression (Fincham \& May, 2020). Self-forgiveness can result in fewer negative emotional experiences, since this implies the diminishing of the feeling of guilt and shame. On the other hand, the forgiveness offered to others also diminishes the pondering of the offenses that they have suffered. In this light, the attitudes of forgiveness tend to diminish negative emotional states, increases the sensation of well-being.

People who have a meaning in life, who have a purpose, also tend to present fewer symptoms of depression (Disabato et al., 2017). The experience of a meaningful life tends to be associated with the experiences of happiness, which implies less feelings of anxiety, depression, and stress (Li et al., 2019). In this sense, it is understood that the internalizing symptoms are less frequent in people with a purpose in life.

The HiTOP model incorporates, in the better part of its dimensions, both clinical symptoms and pathological personality traits. Regarding the internalizing personality traits, characterized by negative affections, Iglesia and Solano $(2018 \mathrm{a}, 2018 \mathrm{~b})$ proposed the trait of serenity as opposed to the psychopathological pole of the trait. People with high levels of serenity tend to be characterized by their ability to exercise self-restraint and to maintain a friendly manner in which to deal with interpersonal conflicts (Iglesia \& Solano, S018b).

\section{The Spectra of Thought Disorders}

Regarding the spectrum of Thought Disorders, the symptoms vary from eccentric thoughts to the complete loss of contact with reality (i.e. psychotic conditions). This spectrum comprehends both the schizophrenic and psychotic conditions. One positive psychological resource that seems to heavily oppose the loss of contact with reality is the capacity of mindfulness. The mindfulness can be understood as the capacity to remain actively aware of one's own thoughts, feelings, bodily sensations, and surrounding environment. Meta-analytical studies have observed that interventions that use techniques of mindfulness present positive effects upon the negative symptoms of people diagnosed in the spectrum of schizophrenia (Jansen et al., 2020).

As mentioned above, the spectrum of thought disorders comprehends a great variability at the level of psychological functioning. In lighter cases, which preserve some psychosocial functionality, it was observed that patients with schizophrenia tend to use positive strategies of coping in order to deal with their symptoms (Cohen et al., 2017). In 40 interviewed patients, the authors observed the use of eight types of coping strategies, as follows: behavior of avoidance, the use of help from others, the use of medication, the promotion of cognitive strategies, control of the environment, spiritual engagement, focus on well-being, and occupational involvement. These positive coping strategies can be implemented in intervention programs for people of this spectrum.

When one considers the model of personality traits subjacent to the HiTOP model, the spectrum of Thought Disorders is related to the trait of psychoticism (Kotov et al., 2017). Iglesia and Solano (2018a, 2018b) propose that the positive counterpoint of this trait would be sprightliness. People with a high level of this trait tend to have clear objectives in life and feel active, useful, and confident (Iglesia \& Solano, 2018b). The facets that compose this domain would be the realistic beliefs and fantasies, uprightness, and perspicacity, as opposed to the pathological facets of beliefs and uncommon experiences, eccentricity, and perceptual deregulation, respectively (Iglesia \& Solano, 2018a).

\section{The Disinhibited Externalizing Spectra}

The Disinhibited Externalizing spectrum is related to the lack of self-control, in which people act impulsively, irresponsibly, and imprudently. This spectrum is also characterized by problems related to substance abuse (Kotov, 2017). Considering this psychopathological domain, in which there is a 
flaw in the capacity to postpone rewards, a positive psychological resource that can oppose this psychological functioning could be self-determination. For positive psychology, self-determination refers to a behavior that is freely and intentionally chosen, based on the person's own desire (Wehmeyer \& Little, 2009). While the disinhibited behavior is based solely on the emotional processes, seeking pleasure and/or reducing tension, self-determination is based on autonomy, selfregulation, psychological empowerment, and self-achievement (Wehmeyer \& Little, 2009).

Other variables that can be negatively associated with this domain are self-regulation and selfefficacy. Self-regulation involves the control of one's own thoughts, feelings, and behaviors to achieve long-term goals (Maddux, 2009). Consequently, people with adequate levels of selfregulation tend to be capable of handling impulses so as to be able to achieve their goals. The sense of self-efficacy reflects the believe that people have their own capacity to behave in such a way as to achieve specific goals (Bandura, 1977). In this light, people that believe in their ability to exercise control over themselves tend to act in a controlled and responsible manner.

Regarding traits, the Disinhibited Externalizing spectrum was set against the trait of moderation in the positive traits model (Iglesia \& Solano, 2018a, 2018b). People with a high level of moderation are characterized as being prudent, as they plan their actions, avoiding unnecessary risks (Iglesia \& Solano, 2018b). People with positive personality traits tend to present behaviors that run contrary to the pathological pole, that is, presenting greater self-control over one's own actions.

\section{The Antagonistic Externalizing Spectra}

Concerning the Antagonistic Externalizing spectrum, the associated symptoms are related to rude, antisocial, and hostile conducts, including insensitivity and dishonesty towards others, in addition to physical aggression (Kotov, 2017). This factor is easily opposed to the constructs of empathy (Stocks \& Lishner, 2009), altruism (Lishner \& Stocks, 2009), authenticity (Sheldon, 2009), honesty (Thorkildsen \& Hanus, 2009a), and civility (Thorkildsen \& Hanus, 2009b).

Iglesia and Solano (2018a, 2018b) proposed the domain of integrity as opposed to the antagonistic personality traits. People with a high level of this domain tend to be reliable, honest, and truthful, and present themselves as they truly are (Iglesia \& Solano, 2018b). Kaufman et al. (2019) proposed the light triad as opposed to the dark triad of personality. The three factors proposed by these authors are kantianism, humanism, and faith in humanity. These behavioral standards tend to favor positive relations with people, in such a way that others feel comfortable in interactions, which can result in a perception of well-being and social health.

\section{The Detachment Spectra}

The Detachment spectrum is related to the lack of involvement with others. This spectrum includes symptoms of interpersonal passivity, social reclusion, avoiding intimacy, the lack of pleasure in activities, among others (Kotov, 2017). This spectrum primarily reflects the schizoid, schizotypal, and paranoid characteristics of social distancing, as well as superficiality and theatricality of interpersonal relationships of the histrionic style of personality. Flourishing relationships are those that promote well-being and mental health (Snyder \& Lopez, 2007). The maintenance of friendships is directly associated with happiness (Sanches et al., 2020) and people who had close relationships during adolescence tend to have great mental health during the adulthood (Narr et al., 2019). These positive factors oppose to detachment symptoms.

While in the detachment spectrum one can find personality traits of social reclusion and the avoidance of intimacy, Iglesia and Solano (2018a, 2018b) indicate that the dimension of humanity is characterized by the traits of sociability and willingness for intimacy. People with a high level of this 
trait tend to be available for others and interested in the needs of others (Iglesia \& Solano, 2018b). Contrary to the trait of detachment, people with a high level in humanity actively seek interpersonal contact, interested in profound and lasting connections with others. This pattern of behavior, as well as of integrity, can be associated with the increase in social well-being.

\section{Final Considerations and Future Outlook}

The present article sought to understand the processes of mental health and mental illness through a theoretical-conceptual reading, articulating a dimensional model of psychopathology to positive psychological variables. While psychopathology reflects unpleasant subjective experiences, which can lead to psychosocial damage, well-being and mental health are characterized by thoughts, feelings, and behaviors that bring satisfaction and happiness. The theoretical articulations proposed in this article need to be empirically validated in such a way as to achieve an integrated and wellfounded model of mental health and mental illness. It is understood that positive psychological resources can be factors of protection and intervention for psychopathological symptoms and traits. The identification of an empirically-based model that includes these facets of the process of mental health and mental illness can provide key inputs for the proposal of programs geared toward the promotion and prevention of mental health, as well as psychopathological intervention and treatment.

\section{ACKNOWLEDGEMENTS}

The present study was financed by means of the Term of Decentralized Execution, logged under protocol number $N^{0}$ 6/2019/DPSP/SENASP, approved by the Brazilian Ministry of Justice and Public Security and the University of Brasilia.

\section{REFERENCES}

Achenbach, T. M. (2020). Bottom-Up and top-down paradigms for psychopathology: A half-century odyssey. Annual Review of Clinical Psychology, 16(1), 1-24. https://doi.org/10.1146/annurevclinpsy-071119-115831

American Psychiatric Association (1980). Diagnostic and Statistical Manual of Mental Disorders, Third Edition (DSM-III). American Psychiatric Publishing.

Bailey, A. J., \& Finn, P. R. (2019). Borderline personality disorder symptom comorbidity within a high externalizing sample: Relationship to the internalizing-externalizing dimensional structure of psychopathology. Journal of Personality Disorders, 34(6), 814-826. https://doi.org/10.1521/pedi_2019_33_415

Bandura, A. (1977). Self-efficacy: Toward a unifying theory of behavioral change. Psychological Review, 84(2), 191-215. https://doi.org/10.1016/0146-6402(78)90002-4

Chakhssi, F., Kraiss, J. T., Sommers-Spijkerman, M., \& Bohlmeijer, E. T. (2018). The effect of positive psychology interventions on well-being and distress in clinical samples with psychiatric or somatic disorders: A systematic review and meta-analysis. BMC psychiatry, 18(1), 211. https://doi.org/10.1186/s12888-018-1739-2

Carvalho, L. F., \& Primi, R. (2018). Inventário Dimensional Clínico da Personalidade 2 (IDCP2) e Inventário Dimensional Clínico da Personalidade - versão triagem (IDCP-triagem). Pearson. 
Sérgio Oliveira, Felipe Corrêa, Wladimir Fonseca, Daniela Zanini, Germano Esteves, Giulia Melo, Sebastião Pereira Júnior, Thiago Nascimento, \& Cristiane Faiad

Carvalho, L. F., Sette, C. P., \& Ferrari, B. L. (2019). Development of a Scale to Measure Histrionic Traits According to the Hierarchical Taxonomy of Psychopathology. Trends in Psychology, 27(3), 707-720. https://doi.org/10.9788/tp2019.3-08

Carvalho, L. F., Ferraz, A. S., \& Otoni, F. (2020). Development of the Dimensional Clinical Personality Inventory - Avoidant version based on the HiTOP. Avaliação Psicológica, 19(1), 2937. https://doi.org/10.15689/ap.2020.1901.17046.04

Carvalho, L. F., Pianowski, G., Bacciotti, J., \& Reis, A. M. (2018). Assessing borderline personality disorder based on the Hierarchical Taxonomy of Psychopathology (HiTOP): Dimensional Clinical Personality Inventory 2-BPD. Archives of Psychiatry and Psychotherapy, 4, 77-87. https://doi.org/10.12740/APP/99146

Caspi, A., Houts, R. M., Belsky, D. W., Goldman-Mellor, S. J., Harrington, H., Israel, S., Meyer, M. H., Ramrakha, S., Shalev, I., Poulton, R., \& Moffitt, T. E. (2014). The p factor: one general psychopathology factor in the structure of psychiatric disorders?. Clinical Psychological Science, 2(2), 119-137. https://doi.org/10.1177/2167702613497473

Cohen, A. N., Hamilton, A. B., Saks, E. R., Glover, D. L., Glynn, S. M., Brekke, J. S., \& Marder, S. R. (2017). How occupationally high-achieving individuals with a diagnosis of schizophrenia manage their symptoms. Psychiatric Services, 68(4), 324-329. https://doi.org/10.1176/appi.ps.201600031

Conway, C. C., Forbes, M. K., Forbush, K. T., Fried, E. I., Hallquist, M. N., Kotov, R., MullinsSweatt, S. N., Shackman, A. J., Skodol, A. E., South, S. C., Sunderland, M., Waszczuk, M. A., Zald, D. H., Afzali, M. H., Bornovalova, M. A., Carragher, N., Docherty, A. R., Jonas, K. G., Krueger, R. F., ... Eaton, N. R. (2019). A Hierarchical Taxonomy of Psychopathology Can Transform Mental Health Research. Perspectives on psychological science: a journal of the Association for Psychological Science, $\quad$ 14(3), 419-436. https://doi.org/10.1177/1745691618810696

Clark, L. A., Watson, D., \& Reynolds, S. (1995). Diagnosis and classification of psychopathology: Challenges to the current system and future directions. Annual review of psychology, 46(1), 121153. https://doi.org/10.1146/annurev.ps.46.020195.001005

Dewsaran-van der Ven, C., van Broeckhuysen-Kloth, S., Thorsell, S., Scholten, R., De Gucht, V., \& Geenen, R. (2018). Self-compassion in somatoform disorder. Psychiatry research, 262, 34-39. https://doi.org/10.1016/j.psychres.2017.12.013

Disabato, D. J., Kashdan, T. B., Short, J. L., \& Jarden, A. (2017). What predicts positive life events that influence the course of depression? A longitudinal examination of gratitude and meaning in life. Cognitive Therapy and Research, 41(1), 444-458. https://doi.org/10.1007/s10608-016-9785$\mathrm{x}$

Fincham, F. D., \& May, R. W. (2020). Divine, interpersonal and self-forgiveness: Independently related to depressive symptoms? The Journal of Positive Psychology, 15(4), 448-454. https://doi.org/10.1080/17439760.2019.1639798

Galvão, T. F., Pansani, T. D. S. A., \& Harrad, D. (2015). Principais itens para relatar Revisões sistemáticas e Meta-análises: A recomendação PRISMA. Epidemiologia e Serviços de Saúde, 24, 335-342. https://doi.org/10.5123/S1679-49742015000200017

He, Q., \& Li, J. J. (2020). Factorial invariance in hierarchical factor models of mental disorders in African American and European American youths. Journal of Child Psychology and Psychiatry. https://doi.org/10.1111/jcpp.13243

Hyland, P., Murphy, J., Shevlin, M., Bentall, R. P., Karatzias, T., Ho, G. W.K., Boduszek, D., \& McElroy, E. (2020). On top or underneath: Where does the general factor of psychopathology fit within a dimensional model of psychopathology among trauma survivors? Psychological Medicine, 1-11. https://doi.org/10.1017/S003329172000104X 
Iglesia, G., \& Solano, A. C. (2018). El Inventario de Rasgos de Personalidad Positivos (IRP-5): Construcción y análisis psicométricos básicos preliminares. Perspectivas en Psicología, 15, 4657. https://www.redalyc.org/articulo.oa?id=483555971005

Iglesia, G., \& Solano, A. C. (2018). The Positive Personality Model (PPM): Exploring a New Conceptual Framework for Personality Assessment. Frontiers in psychology, 9, 2027. https://doi.org/10.3389/fpsyg.2018.02027

Jacobs, I., Lenz, L., Wollny, A., \& Horsch, A. (2018). The Higher-Order Structure of Schema Modes. Journal of Personality Disorders, 34(3), 348-376. https://doi.org/10.1521/pedi_2018_32_401

Jansen, J. E., Gleeson, J., Bendall, S., Rice, S., \& Alvarez-Jimenez, M. (2020). Acceptance-and mindfulness-based interventions for persons with psychosis: A systematic review and metaanalysis. Schizophrenia research, 215, 25-37. https://doi.org/10.1016/j.schres.2019.11.016

Karampas, K., Michael, G., \& Stalikas, A. (2016). Positive Emotions, Resilience and Psychosomatic Heath: Focus on Hellenic Army NCO Cadets. Psychology, 7, 1727-1740. https://doi.org/10.4236/psych.2016.713162

Kaufman, S. B., Yaden, D. B., Hyde, E., \& Tsukayama, E. (2019). The light vs. dark triad of personality: Contrasting two very different profiles of human nature. Frontiers in psychology, 10, 467. https://doi.org/10.3389/fpsyg.2019.00467

Kotov, R., Krueger, R. F., \& Watson, D. (2018). A paradigm shift in psychiatric classification: the Hierarchical Taxonomy Of Psychopathology (HiTOP). World Psychiatry, 17(1), 24-25. https://doi.org/10.1002/wps.20478

Kotov, R., Krueger, R. F., Watson, D., Achenbach, T. M., Althoff, R. R., Bagby, R. M., Brown, T., Carpenter, W., Caspi, A., Clark, L., Eaton, N., Forbes, M., Forbush, K., Goldberg, D., Hasin, D., Hyman, S., Ivanova, M., Lynam, D., Markon, K., ... Zimmerman, M. (2017). The Hierarchical Taxonomy of Psychopathology (HiTOP): a dimensional alternative to traditional nosologies. Journal of abnormal psychology, 126(4), 454-477. https://doir.org/10.1037/abn0000258

Kotov, R., Jonas, K. G., Carpenter, W. T., Dretsch, M. N., Eaton, N. R., Forbes, M. K., Forbush, K., Hobbs, K., Reininghaus, U., Slade, T., South, S., Sunderland, M., Waszczuk, M., Widiger, T., Wright, A., Zald, D., Krueger, R., Watson, D., \& HiTOP Utility Workgroup . (2020). Validity and utility of Hierarchical Taxonomy of Psychopathology (HiTOP): I. Psychosis superspectrum. World Psychiatry, 19(2), 151-172. https://doir.org/10.1002/wps.20730

Krueger, R. F., Caspi, A., Moffitt, T. E., \& Silva, P. A. (1998). The structure and stability of common mental disorders (DSM-III-R): a longitudinal-epidemiological study. Journal of abnormal psychology, 107(2), 216-227. https://doi.org/10.1037/0021-843X.107.2.216

Krueger, R. F., Derringer, J., Markon, K. E., Watson, D., \& Skodol, A. E. (2012). Initial construction of a maladaptive personality trait model and inventory for DSM-5. Psychological Medicine, 8, 112. https://doi.org/10.1017/S0033291711002674

Krueger, R. F., Kotov, R., Watson, D., Forbes, M. K., Eaton, N. R., Ruggero, C. J., Simms, L., Widiger, T., Achenbach, T., Bach, B., Bagby, R., Bornovalova, M., Carpenter, W., Chmielewski, M., Cicero, D., Clark, L., Conway, C., DeClercq, B., DeYoung, C., .... Zimmermann, J.. (2018). Progress in achieving quantitative classification of psychopathology. World Psychiatry, 17(3), 282-293. https://doi.org/10.1002/wps.20566

Krueger, R. F., \& Piasecki, T. M. (2002). Toward a dimensional and psychometrically-informed approach to conceptualizing psychopathology. Behaviour Research and Therapy, 40(5), 485-499. https://doi.org/10.1016/S0005-7967(02)00016-5

Latzman, R. D., DeYoung, C. G., \& Workgroup, H. N. F. (2020). Using empirically-derived dimensional phenotypes to accelerate clinical neuroscience: The Hierarchical Taxonomy of Psychopathology (HiTOP) framework. Neuropsychopharmacology, 45(7), 1083-1085. https://doi.org/0.1038/s41386-020-0639-6 
Sérgio Oliveira, Felipe Corrêa, Wladimir Fonseca, Daniela Zanini, Germano Esteves, Giulia

Melo, Sebastião Pereira Júnior, Thiago Nascimento, \& Cristiane Faiad

Li, P. J., Wong, Y. J., \& Chao, R. C. L. (2019). Happiness and meaning in life: Unique, differential, and indirect associations with mental health. Counselling Psychology Quarterly, 32(3-4), 396-414. https://doi.org/10.1080/09515070.2019.1604493

Lin, C. C. (2019). Gratitude, positive emotion, and satisfaction with life: A test of mediated effect. Social Behavior and Personality: an international journal, 47(4), 1-8. https://doi.org/10.2224/sbp.4398

Lishner, D. A., \& Stocks, E. L. (2009). Altruism. In S. J. Lopez (Ed.), The encyclopedia of positive psychology (pp. 32-38). Wiley-Blackwell.

Longenecker, J. M., Krueger, R. F., \& Sponheim, S. R. (2020). Personality traits across the psychosis spectrum: A Hierarchical Taxonomy of Psychopathology conceptualization of clinical symptomatology. Personality and mental health, 14(1), 88-105. https://doi.org/10.1002/pmh.1448

Maddux, J. E. (2009). Self-regulation. In S. J. Lopez (Ed.), The encyclopedia of positive psychology (pp. 889-893). Wiley-Blackwell.

Markon, K. E., Chmielewski, M., \& Miller, C. J. (2011). The reliability and validity of discrete and continuous measures of psychopathology: a quantitative review. Psychological bulletin, 137(5), 856-879. https://doi.org/10.1037/a0023678

Meehan, K. B., Siefert, C., Sexton, J., \& Huprich, S. K. (2019). Expanding the Role of Levels of Personality Functioning in Personality Disorder Taxonomy: Commentary on "Criterion A of the AMPD in HiTOP". Journal of personality assessment. 101. 367-373. https://doi.org/10.1080/00223891.2018.1551228

Millon, T. (1991). Classification in psychopathology: Rationale, alternatives, and standards. Journal of Abnormal Psychology, 100(3), 245-261. https://doi.org/10.1037/0021-843X.100.3.245

Mullins-Sweatt, S. N., Hopwood, C. J., Chmielewski, M., Meyer, N. A., Min, J., Helle, A. C., \& Walgren, M. D. (2020). Treatment of personality pathology through the lens of the hierarchical taxonomy of psychopathology: Developing a research agenda. Personality and Mental Health, 14(1), 123-141. https://doi.org/10.1002/pmh.1464

Narr, R. K., Allen, J. P., Tan, J. S., \& Loeb, E. L. (2019). Close friendship strength and broader peer group desirability as differential predictors of adult mental health. Child development, 90(1), 298313. https://doi.org/10.1111/cdev.12905

Perkins, E. R., Joyner, K. J., Patrick, C. J., Bartholow, B. D., Latzman, R. D., DeYoung, C. G., ... \& Docherty, A. R. (2020). Neurobiology and the Hierarchical Taxonomy of Psychopathology: progress toward ontogenetically informed and clinically useful nosology. Dialogues in Clinical Neuroscience, 22(1), 51-63. https://doi.org/10.31887/DCNS.2020.22.1

Perkins, E. R., Latzman, R. D., \& Patrick, C. J. (2019). Interfacing neural constructs with the Hierarchical Taxonomy of Psychopathology: "Why" and "how." Personality and Mental Health, 14(1), 106-122. https://doi.org/10.1002/pmh.1460

Petrocchi, N., \& Couyoumdjian, A. (2015). The impact of gratitude on depression and anxiety: the mediating role of criticizing, attacking, and reassuring the self. Self and Identity, 15(2), 191-205. http://dx.doi.org/10.1080/15298868.2015.1095794

Pianowski, G., Carvalho, L. F., \& Miguel, F. K. (2019). Investigating the Spectra constellations of the Hierarchical Taxonomy of Psychopathology (HiTOP) model for personality disorders based on empirical data from a community sample. Brazilian Journal of Psychiatry, 41, 148-152. https://dx.doi.org/10.1590/1516-4446-2018-0015

Reed, G. M. (2018). HiTOP must meet the use requirements of the ICD before it can aspire to replace it. World psychiatry: Official journal of the World Psychiatric Association (WPA), 17(3), 296-298. https://doi.org/10.1002/wps.20560

Ruggero, C. J., Kotov, R., Hopwood, C. J., First, M., Clark, L. A., Skodol, A. E., Mullins-Sweatt, S. N., Patrick, C. J., Bach, B., Cicero, D. C., Docherty, A., Simms, L. J., Bagby, R. M., Krueger, R. 
F., Callahan, J. L., Chmielewski, M., Conway, C. C., De Clercq, B., Dornbach-Bender, A., . . . Zimmermann, J. Integrating the Hierarchical Taxonomy of Psychopathology (HiTOP) into clinical practice. Journal of consulting and clinical psychology, 87(12), 1069-1084. https://doi.org/10.1037/ccp0000452

Salum, G. A. Junior., Gadelha, A., Polanczyk, G. V., Miguel, E. C., \& Rohde, L. A. P. (2018). Diagnostic operationalization and phenomenological heterogeneity in psychiatry: the case of attention deficit hyperactivity disorder. Salud mental, 41(6), 249-259. https://doi.org/10.17711/SM.0185-3325.2018.037

Sanchez, M., Haynes, A., Parada, J. C., \&amp; Demir, M. (2020). Friendship maintenance mediates the relationship between compassion for others and happiness. Current Psychology, 39(2), 581592. https://doi.org/10.1007/s12144-017-9779-1

Sellbom, M., Carragher, N., Sunderland, M., Calear, A. L., \& Batterham, P. J. (2020). The role of maladaptive personality domains across multiple levels of the HiTOP structure. Personality and Mental Health, 14(1), 30-50. https://doi.org/10.1002/pmh.1461

Sheldon, K. M. (2009). Authenticity. In S. J. Lopez (Ed.), The encyclopedia of positive psychology (pp. 75-78). Wiley-Blackwell.

Snyder, C. R., \& Lopez, S. J. (2007). Positive psychology: The scientific and practical explorations of human strengths. Sage Publications.

Stocks, E. L., \& Lishner, D. A. (2009). Emphaty. In S. J. Lopez (Ed.), The encyclopedia of positive psychology (pp. 320-326). Wiley-Blackwell.

Thorkildsen, A. T., \& Hanus, K. M. (2009a). Honesty. In S. J. Lopez (Ed.), The encyclopedia of positive psychology (pp. 484-487). Wiley-Blackwell.

Thorkildsen, A. T., \& Hanus, K. M. (2009b). Civility. In S. J. Lopez (Ed.), The encyclopedia of positive psychology (pp. 160-162). Wiley-Blackwell.

Tomiatti, M., Gore, W. L., Lynam, D. R., Miller, J. D., \& Widiger, T. A. (2012). A five-factor measure of histrionic personality traits. In A. M. Columbus (Ed.), Advances in psychology research (Vol. 87, pp. 113-138). Nova Science Publishers.

van Bork, R., Epskamp, S., Rhemtulla, M., Borsboom, D., \& van der Maas, H. L. (2017). What is the p-factor of psychopathology? Some risks of general factor modeling. Theory \& Psychology, 27(6), 759-773. https://doi.org/10.1177/0959354317737185

Verheul, R. (2005). Clinical utility of dimensional models for personality pathology. Journal of personality disorders, 19(2), 283-302. https://doi.org/10.1521/pedi.2005.19.3.283

Wehmeyer, M. L., \& Little, T. D. (2009) Self-Determination. In S. J. Lopez (Ed.), The encyclopedia of positive psychology (pp. 868-874). Wiley-Blackwell.

Widiger, T. A., \& Sankis, L. M. (2000). Adult psychopathology: Issues and controversies. Annual Review of Psychology, 51(1), 377-404. https://doi.org/10.1146/annurev.psych.51.1.377

Widiger, T. A., \& Mullins-Sweatt, S. (2012). Mental disorders as discrete clinical conditions: Dimensional versus categorical classification. In M. Hersen, D. Beidel, \& S. Turner, Adult psychopathology and diagnosis (6th ed., pp. 3-32). Wiley.

Widiger, T. A., \& Gore, W. L. (2015). Dimensional versus Categorical Models of Psychopathology. The Encyclopedia of Clinical Psychology, 1-12. https://doi.org/10.1002/9781118625392.wbecp108

Widiger, T. A., Bach, B., Chmielewski, M., Clark, L. A., DeYoung, C., Hopwood, C. J., Kotov, R., Krueger, R. F., Miller, J. D., Morey, L. C., Mullins-Sweatt, S. N., Patrick, C. J., Pincus, A. L., Samuel, D. B., Sellbom, M., South, S. C., Tackett, J. L., Watson, D., Waugh, M. H., .. . Thomas, K. M. (2019). Criterion a of the AMPD in HiTOP. Journal of Personality Assessment, 101(4), 345-355. https://doi.org/10.1080/00223891.2018.1465431 
Sérgio Oliveira, Felipe Corrêa, Wladimir Fonseca, Daniela Zanini, Germano Esteves, Giulia Melo, Sebastião Pereira Júnior, Thiago Nascimento, \& Cristiane Faiad

Wittchen, H. U., \& Beesdo-Baum, K. (2018). "Throwing out the baby with the bathwater"? Conceptual and methodological limitations of the HiTOP approach. World Psychiatry, 17(3), 298. https://doi.org/10.1002/wps.20561

Wright, A. G., Krueger, R. F., Hobbs, M. J., Markon, K. E., Eaton, N. R., \& Slade, T. (2013). The structure of psychopathology: toward an expanded quantitative empirical model. Journal of abnormal psychology, 122(1), 281-294. https://doi.org/10.1037/a0030133 